\title{
Application Research of BIM Technology in Fine Engineering Cost Management
}

\author{
Yan Wang \\ School of Economics and Management, Tianjin Chengjian University, Tianjin, 300384, China
}

Keywords: fine management, engineering cost, BIM technology

\begin{abstract}
The precise management of engineering cost is on the premise of precise execution, which will reduce the project cost in every stage. The fine management of the project cost makes the cost management process conform to the demand of precision and standardization, greatly improving the effectiveness of the project cost management. BIM technology is precise, complete with convenient information transmission. Based on the above analysis, the paper explores the application strategies of BIM technology in fine management of engineering cost to provide some references for the relative researchers.
\end{abstract}

\section{Introduction}

With the continuous development of social economy, the construction business in China has been flourishing [1]. It has been widely concerned and has great influence on people's life. We must attach great importance to it. In the construction project management, the cost management of the project is an important part of the construction project, which is beneficial to the effective control of the cost and cost of the construction project. Project cost management must be run through the whole construction project. We should supervise the whole process of construction cost to optimize the resource allocation of construction projects and improve the utilization ratio of funds. However, the effect of the project cost management implemented at this stage is not good, and the "three super" problem often appears. To improve this situation, the state must give some support to provide a good cost management environment for construction projects, and enterprises should innovate the cost management measures to improve the effectiveness of project cost management and adopt refined project cost management. The BIM information technology can be fully applied to ensure the quality of the project cost management when the project cost meticulous management is carried out. BIM is a building information model, which has the features of visualization, coordination, optimization, simulation and even drawing. BIM does not simply summarize digital information but uses digital information in all stages of the whole project. No matter in terms of project planning or project maintenance, it can simulate corresponding data. To find out defects of architectural project, for the specific problem using the corresponding solution, it will not make the day after maintenance to increase the difficulty, also can significantly enhance the construction efficiency of construction, saving construction in terms of capital investment, reduce the risk of building contractors' investment funds. And the application of BIM is also conducive to the rapid modification of the project planning plan for the simulation problem to achieve the best effect and maximize its own interests [2].

\section{Connotation of Fine Management of Engineering Cost}

\subsection{Significance of Fine Management of Engineering Cost}

Project cost management is refined in order to change the current project cost management problems, it is from two aspects to determine the project cost and cost control to the management process decomposition to refine the specific aspects of the work, through the pursuit of new technology and new method, the correct analysis of the project cost, build a good control program, make the cost the management process conforms to the accuracy and standardization of the requirements, so as to improve the effectiveness of project cost management. In the early stage of the project, the goal of controlling the decision is achieved. In the decision-making stage of the project, it is necessary to ensure that the investment estimation of the project is the maximum limit of the total 
cost of the project. Among them, the investment estimate directly controls the design budget, so the accuracy is higher. Therefore, the budget of the construction drawings must be guided to optimize the design budget. At the stage of bidding, the core of the cost management lies in the contract price. It is necessary to consider the project plan and the actual implementation to determine the advance payment and progress. In the completion of settlement phase, the overall cost of the project needs to be collected, and the various stages of the project need to be controlled.

\subsection{Patterns of Fine Management of Engineering Cost}

Due to the phase and dynamic characteristics of the project cost, the data and information of the large related projects are derived from all stages of the project cost management. The degree of refinement of cost management is to ensure the correct creation of the corresponding data information in the sharing of each other in the project [3]. Only a careful and rigorous cost management process of cost data and information can make it run more efficiently, so that managers can take the right decision. The main way to carry out fine management is to use advanced data and even information technology. Project cost fine is mainly refers to the time to carry out the work of project cost management, to follow the fine, accurate and detailed and strict principles, can be the work of project cost management into a small part of each, pay attention to control of the project cost, make full use of human resources, not only to the construction technology of the cost management, but also to strengthen the control of Engineering contract.

\subsection{Directions of Fine Management of Engineering Cost}

Project execution cost ideas of fine management in the current project cost management mode, the maximum value of the completed project cost management, cost management weaknesses deep development project, and the integration of advanced information technology, data and system management technology, innovate management way, make the project cost management by experience of management into standardized, accurate, standardized management. The project cost with big data to refine each stage of the construction cost, showing the construction status of each stage, to grasp the problems and building materials used in the construction process; and the technology can accurately deepen reinforced cast-in-place concrete, and reflected in the drawings. The fine management of the project cost requires the implementation of the cost management of the whole life cycle of the project to avoid the three-super phenomenon. The content of the fine management of engineering cost is mainly distributed in five stages, namely, the estimation stage of project investment, the stage of engineering design and construction budget, and the completion stage of contract issuing contract price.

\section{Application Advantages of BIM Technology in Fine Management of Engineering Cost}

\subsection{Precise Information Transmission}

BIM includes information storage and information calculation of two, its main content through the most basic understanding of product suppliers, and the classification, solves the problem of large amount of information content of complex problems. In the process of BIM precision management, the 3D effect in the BIM model can be used to help the construction of the whole model of the project design to obtain the design content directly. In the process of BIM meticulous management, it can also transmit the project's expectations, reduce the cost risk of building a single book, for example, problems existing in different structural devices, we can screen unreasonable components, and eliminate the missing items, missing items and heavy items. The BIM model gives computer technology, which can achieve fast and accurate computation. The parameterization features make all relevant information updated synchronously and improve the speed of data updating and aggregation. The BIM model, with its 3D effect, allows the construction unit to express the design content and the theme more accurately. Not only that, the establishment of the BIM model can directly obtain the computable attributes of a part of the product. The BIM model can express the project directly, the trial map with the professional staff and lower requirements, and convenient construction units can 
form overall virtual finished building a comprehensive understanding of the official before the operation. It can make it more accurate to express the expected target to the design unit, reduce the design change in the construction process to the lowest, reduce the construction risk. The BIM model has good visualization effect. When examining the cost, it can quickly find out the unsuitable components with the help of the good visual effect of the BIM model, and build and eliminate them accordingly. Reduce the error and reduce the risk of the cost of the project. The BIM model, with its parameterized characteristics, makes the model more linkage, prevents the delay of construction progress and increases the unnecessary cost of the project.

\subsection{Complete Information Transmission}

During the whole construction project, due to the long duration, it will involve the subjects in different stages. During the process of manipulation, the software and uploading data of different entities are different, which will create obstacles for each stage of work communication and will also cause information loss. By using BIM model, information integration in different stages of construction projects can reduce the probability of data transformation unchanged, different versions and incomplete database data. Besides, BIM can collate and integrate different stages of information, and convey the purpose and process of each stage effectively, effectively linking up, and reducing information loss. Usually, construction projects have a long construction cycle, and their working bodies are different at different stages. Due to the different software used by different subjects, the phenomenon of data communication is blocked and data information is missing. After using BIM model, can integrate the whole project information in the model, and can deliver the information fast and complete, to design, construction, real fast transfer to the relevant departments, effectively reduce the loss caused by the omission of information. Moreover, the BIM model can enable the construction unit to express the project requirements accurately and ensure that information can be delivered accurately and completely in the design stage, and then effectively control the cost of project construction, because of its good view effect and limited presupposition function. In the process of compiling the funds, the BIM can effectively collect and integrate the cost information in the construction and embody the dynamic situation of the funds.

\subsection{Convenient Information Transmission}

In the application of BIM model, due to the different design units of different design software, the relationship between the vital interests of secret information, lead to the design of units of information exchange is usually through the 2D drawing, the information sharing degree is low, the information communication is slow, long and complex information channel. After the application of the BIM model, the BIM is built on the common platform, and the general standard is used to describe the architecture and the components of the building, to provide a perfect information sharing service. The integrated model of the same platform can coordinate with each other, establish timely and effective communication and cooperation, to avoid conflict in the model construction. Traditional engineering cost management will be designed through many aspects such as architectural design, structural design, professional design and energy saving. The process is complex and the workload is heavy. It is inevitable that there will be disputes between parties because of different opinions in the process of construction. The application of BIM model can reduce these unnecessary links, and different software can be used according to the different design units in the BIM model. At the same time, on the BIM platform, the resources sharing, the establishment of timely and effective communication and cooperation, improve the speed of information communication, the long information channel problem. At the same time, the model can also effectively coordinate the work of participants, enhance communication among all parties, and enable parties to coordinate and cooperate with each other to reduce unnecessary contradictions. Not only that, design units can also build remote monitoring project design situation by BIM platform, and make corresponding coordination and adjustment work, which not only reduces the cost of program modification, but also reduces the risk caused by design change. In addition, BIM model can predict project accurately and update records timely combined with actual construction conditions, which makes it more convenient to carry out meticulous management of project cost [4]. 


\section{Application Strategies of BIM Technology in Fine Management of Engineering Cost}

In the design stage, by establishing the BIM model of Electromechanical, structural and architectural aspects, and introducing different professional inspection software into the model for collision detection, the efficiency of engineering drawing is greatly improved. Moreover, the function of collision detection can fundamentally reduce the design change caused by collisions among different professions, so that we can achieve early warning and effectively control the design cost in the early stage. The related staff can import mechanical and structural BIM models to BIM cost software, so that they can quickly carry out the two processing, to get accurate basic data of engineering quantity. The resources and manpower saved can be better used to analyze data and use value engineering method to analyze the cost data in the design stage at the economic level. At the same time, the historical data of similar projects stored in the BIM database can be extracted and compared effectively. The result is submitted to the designer, to provide a reliable reference for the development of the design work. According to the above analysis, we can find that BIM technology is applied in the cost management of the engineering design stage, and its work is mainly focused on the design of cost data and the participation of all parties involved in cost interaction. The use of BIM technology can effectively build, analyze, store and interactively use information and data, and effectively combine design work and cost management work, comprehensively optimize the engineering design, and strengthen the control of the early stage project cost. Moreover, BIM can reflect the collision problems between different professions in the design process quickly and accurately based on its simulation and collision analysis functions, to avoid design change in later stage design. The bidder can use the BIM model issued by the tendered to check the volume of the list, which greatly improves the progress of the bidding price preparation, to reserve more time for quotation analysis. Moreover, bidders can get the latest market prices through BIM cloud and enterprise BIM database, and make in-depth research on bidding strategies, to achieve the best competitiveness of bidding.

\section{Conclusions}

The implementation of BIM project cost refinement management improves the efficiency of the project construction. BIM technology ensures the integrity and precision of information, speeds up the speed of information processing, and achieves the effect of the implementation of the fine management of the project cost. BIM technology can effectively solve the information problems in management, improve the efficiency and effect of the project, and thus promote the sustainable, stable and healthy development of the construction industry.

\section{References}

[1] Sun Junling. Research on the fine management of engineering cost based on BIM [J]. Journal of Hunan City University (Natural Science), 2016, 25(4): 17-18.

[2] Ji Boya, Jin Zhanyong, Qi Zhenqiang. Project Cost of Refinement Management Research Application of BIM [J]. Journal of Beijing University of Civil Engineering and Architecture, 2013, 29(4): 76-80.

[3] Zhang Hong. Research on the fine management of engineering cost based on BIM [J]. Engineering Construction, 2017, 49(2): 90-93.

[4] Wang Bin. The Application Value of BIM Technology in Engineering Cost of Fine Management [J]. Construction \& Design for Engineering, 2017(6): 186-187. 